\title{
Self-efficacy as a mediator of the relationship between meaning in life and subjective well-being in cardiac patients
}

\author{
Dariusz Krok (D) A,B,C,D,E, Rafat Gerymski (D) D,E,F \\ Institute of Psychology, University of Opole, Poland
}

BACKGROUND

The theoretical framework and empirical data suggest that the relationship between meaning in life and well-being might be mediated by self-efficacy. Based on the cognitive-affective processing system (CAPS), self-concordance model and empirical data, we assume that self-efficacy might also act as a mediator between meaning in life and subjective well-being in cardiac patients.

PARTICIPANTS AND PROCEDURE

This study was conducted in cardiology units in Poland. Patients who met the inclusion/exclusion criteria were approached by research assistants in the inpatient clinic and outpatient centre in a cardiology unit in Poland. Results of the 176 participants ( 82 women and 94 men) aged from 45 to 82 years $(M=58.56, S D=8.25)$ were included in this study.

RESULTS

Meaning in life and self-efficacy were significantly related to the each other and two dimensions of subjective well- being. Using path analysis we confirmed the direct effects of meaning in life on life satisfaction and positive affect and indirect effects of meaning in life on life satisfaction, positive affect, and negative affect. Self-efficacy was found to be a partial mediator in the relationship between meaning in life with life satisfaction and positive affect. As there was no direct path between meaning in life and negative affect, meaning in life was a full mediator between these factors.

\section{CONCLUSIONS}

The present study shows the complexity of the relationship between purpose-oriented personality trait and chronic patients' well-being. This finding provides a solid foundation for further investigation of the influence of personality traits on patients' functioning and well-being.

\section{KEY WORDS}

subjective well-being; self-efficacy; meaning in life; cardiac patients

CORRESPONDING AUTHOR - Prof. Dariusz Krok, Institute of Psychology, University of Opole, 1 A Drzymały Str., 45-342 Opole, Poland, e-mail: dkrok@uni.opole.pl

AUthors' CONTRIBUtion - A: Study design - B: Data collection - C: Statistical analysis · D: Data interpretation .

E: Manuscript preparation · F: Literature search · G: Funds collection

to CITE this ARTICLE - Krok, D., \& Gerymski, R. (2019). Self-efficacy as a mediator of the relationship between meaning

in life and subjective well-being in cardiac patients. Current Issues in Personality Psychology, 7(3), 242-251.

RECEIVED 24.01.2019 · REVIEWED 23.06.2019 • ACCEPTED 24.06.2019 • PUBLISHED 30.09.2019 


\section{BACKGROUND}

The quality of life (QoL) and well-being (WB) of cardiac patients seem to increasingly discussed topics. This should not come as a surprise, as heart failure affects a large part of society (Ho, Pinsky, Kannel, \& Levy, 1993; Roger et al., 2011). Nowadays, many people live with chronic diseases such as heart failure, due to the development of advanced technologies and medical procedures (McGee, 2007). Heart problems are a progressive condition that can cause significant deterioration of well-being, so it is essential to help cardiac patients maintain good well-being by influencing its significant predictors. Since personal resources play an important role in the functioning of the patients (Arvidsdotter, Marklund, Taft, \& Kylén, 2015; Craner et al., 2017), we decided to investigate the relationship of subjective well-being of Polish cardiac patients with two predictors - meaning in life and self-efficacy - which have a significant impact on cardiac patients' well-being (Joekes, Van Elderen, \& Schreurs, 2007; Park, Malone, Suresh, Bliss, \& Rosen, 2008).

\section{MEANING IN LIFE AND WELL-BEING}

Meaning in life is one of the most important predictors of well-being (Frankl, 1963; Krok, 2015a) and is defined as the extent to which people understand the meaning, purpose and importance of their lives (Steger, Kashdan, Sullivan, \& Lorentz, 2008). According to Steger (2012), meaning in life consists of two factors: purpose and comprehension. Purpose is defined as human life aspirations, which stimulate peoples' activity. Comprehension means the ability to understand our lives, environment and how we fit and find ourselves in the surrounding world. Based on a different theoretical perspective, Wong (1998, 2012) proposed that meaning in life contains 7 domains: achievement, relationship, religion, self-transcendence, self-acceptance, intimacy and fair treatment. Nevertheless, meaning in life is a very important motivational force in our lives, which can positively affect our mental health.

Empirical studies show that meaning in life is an important predictor of well-being (Ryff, 1989). It is associated with life satisfaction, positive affect, and negative affect, which are the components of subjective well-being (SWB; Diener, 2009). Subjective wellbeing represents the hedonic aspect of well-being containing the pursuit of happiness. Chamberlain and Zika (1988) point out that meaning in life is positively related to life satisfaction and positive affect and negatively to negative affect. Data provided by Ho, Cheung, and Cheung (2010), Machell, Kashdan, Short, and Nezlek (2015) and Krok and Telka (2018) support their results. Similar relationships have been found in the research of the well-being of chronic patients. Dezutter, Luyckx, and Wachholtz (2015) proved that meaning in life is an important predictor of psychological well-being (PWB) in chronic patients. In addition, Park and colleagues (2008) proved that it is associated with mental and physical components of the health-related quality of life (HRQoL) among congestive heart failure patients.

\section{SELF-EFFICACY AND ITS CONNECTION WITH MEANING IN LIFE AND WELL-BEING}

Self-efficacy is associated with judgments of how well we execute our actions and is required to deal with upcoming situations (Bandura, 1982). It also can be translated as a self-perceived ability to deal with stress (Schwarzer, Bäßler, Kwiatek, Schröder, \& Zhang, 1997). Bandura (1978) states that self-efficacy is a very important determinant of behavioural change. What is more, it contributes to cognitive functioning and development (Bandura, 1993) and differentiates how we behave and think (Bandura, 1995; Pajares, 1996; Schwarzer et al., 1997). Self-efficacy is related to many constructs influencing our well-being. A low sense of self-efficacy is related to symptoms of anxiety or depression (Schwarzer et al., 1997). It is also related to the notion that things happening around us are tougher than in reality (Pajares, 1996). On the other hand, higher level of self-efficacy is associated with better recovery from the setbacks, higher resilience and goal commitment (Pajares, 1996; Schwarzer et al., 1997). It is also related to both meaning in life and well-being (Schulenberg, Smith, Drescher, \& Buchanan, 2016).

DeWitz and colleagues (2009) found that selfefficacy is a significant predictor of meaning in life. Research on quality of life in menopausal women has also proved the importance of that relationship (Jafary, Farahbakhsh, Shafiabadi, \& Delavar, 2011). The correlation between those two constructs can be observed in a study on PTSD among war veterans (Blackburn \& Owens, 2015). Additionally, Korean research revealed that this relationship also occurs in a sample of elders (Byun, Hyun, Park, \& Choi, 2017). Karademas (2006) empirically proved that self-efficacy is related to life satisfaction and optimism. Yoon (2002) and Liu and colleagues (2018) suggested that self-efficacy is positively correlated with optimism, life satisfaction and positive affect, and negatively with negative affect. Other researchers point to the predictive value of self-efficacy for positive and negative affect. Despite the fact that self-efficacy is related to both kinds of affect, those relationships differ in their characteristics. Calandri, Graziano, Borghi, and Bonino (2018) stated that self-efficacy favourably influences positive affect, in opposition to negative affect. Magaletta and Oliver (1999) stated that sig- 


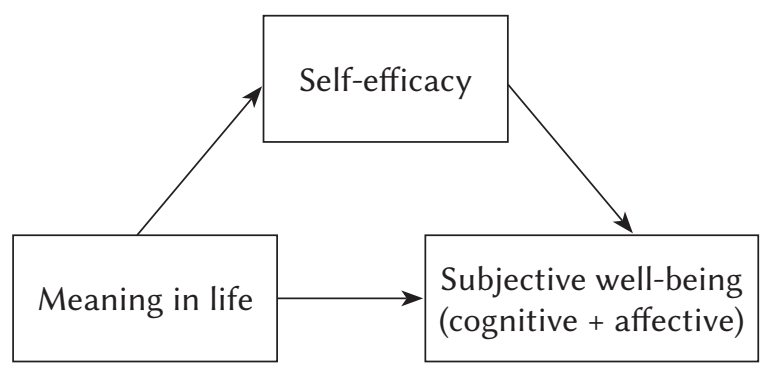

Figure 1. A conceptual model of the mediational role of self-efficacy in the relationship between meaning in life and subjective well-being.

nificant relationships occur between self-efficacy, life satisfaction, and hope. Similar data come from a literature review focused on the role of meaning in life in patients with advanced disease, which pointed out the significance of the relationship between meaning in life, self-efficacy, and well-being (GuerreroTorrelles, Monforte-Royo, Rodríguez-Prat, PortaSales, \& Balaguer, 2017). Interesting results come from a clinical sample of Polish patients. Researchers found that the relationship between life satisfaction, self-efficacy, and meaning in life is significant (Błażek, Kaźmierczak, \& Besta, 2015). A study on congestive heart failure and myocardial infarction patients also demonstrated a significant relationship between self-efficacy and psychological well-being (Joekes et al., 2007). It is proven that self-efficacy has an important impact on the psychological and social spheres of functioning of coronary heart disease patients (Sullivan, Lacroix, Russo, \& Katon, 1998) and quality of life of patients after stroke (RobinsonSmith, Johnston, \& Allen, 2000).

\section{A POTENTIAL MEDIATIONAL ROLE OF SELF-EFFICACY}

Many studies verify simple relationships between meaning in life, self-efficacy, and well-being, but theoretical frameworks and empirical data suggest that the relationship between meaning in life and well-being might be mediated by self-efficacy. Based on the cognitive-affective processing system (CAPS; Mischel \& Shoda, 1995), we can assume that achieving a meaningful goal leads to experiencing positive affect, which in turn translates into positive feedback about the outcomes. According to the CAPS concept, achieving goals (i.e. finding purpose in life) has an impact on our experienced affect (i.e. optimism), which translates into our well-being (Ho et al., 2010). This hypothesis is also supported by the self-concordance model, which states that goal motivation predicts positive expectancies, which in turn predicts greater well-being (Sheldon \& Copper, 2008).
Optimism is not exactly the same construct as selfefficacy, but they are both related (Magaletta \& Oliver, 1999; Krok, 2015b).

Empirical research shows that self-efficacy and optimism mediate the relationship between symptoms of depression and life satisfaction (Karademas, 2006). Ho and colleagues (2010) proved that optimism was a partial mediator between meaning in life and well-being - positive and negative affect. A similar relationship was observed in a group of Polish adolescents - optimism mediated the relationship between meaning in life and two dimensions of well-being: SWB (life satisfaction, positive affect and negative affect) and PWB (Krok \& Telka, 2018). The mediating role of optimism was also significant in the relationship between sense of coherence, subjective, and psychological well-being (Krok, 2015b). Meaning in life is a personality trait, which is similar to the construct of sense of coherence, since both contain ultimate purpose and meaning (Krok, 2015b). Strobel and colleagues (2011) also point out the important mediating role of self-efficacy between personality traits (i.e. neuroticism, extraversion, openness and conscientiousness) and subjective well-being (life satisfaction and happiness). Based on the above theoretical framework and empirical data we assume that self-efficacy might also act as a mediator between meaning in life and subjective well-being in cardiac patients.

\section{AIMS OF THE STUDY}

In the current study, we investigated associations among meaning in life, subjective well-being, and self-efficacy in cardiac patients. Based on previous research, this study examines direct and indirect relationships between meaning in life and cognitive and affective dimensions of subjective well-being in the mediational perspective of self-efficacy. We hypothesize that: (1) meaning in life is positively related to self-efficacy, (2) both meaning in life and self-efficacy are positively related to subjective well-being, (3) self-efficacy mediates the relationship between meaning in life and the cognitive dimension of subjective well-being, (4) self-efficacy is a mediator in the relationship between meaning in life and the affective dimension of subjective well-being. The conceptual model of the relationships proposed in the current research is shown in Figure 1.

\section{PARTICIPANTS AND PROCEDURE}

\section{PARTICIPANTS}

This study was conducted in a cardiology unit in Poland and was part of a larger research programme on cardiac patients. Patients with coronary heart disease 
who were undergoing medical interventions participated in this study. Inclusion criteria were the following: (1) patient had a diagnosis of coronary heart disease, (2) age more than 18 years, (3) ability to read and communicate in Polish, and (4) ability to give informed consent. Exclusion criteria were the following: (1) severe non-cardiovascular comorbidities (e.g. cancer, major psychiatric conditions), (2) pregnancy, (3) inability to fill out a questionnaire for any reason (e.g. cognitive deficiencies, partial blindness), and (4) life-threatening conditions.

Initially, 211 patients were recruited to participate in the study. However, 29 patients were excluded on the basis of inclusion and exclusion criteria, and 6 patients refused to participate (some stated that the study was too exhausting considering their current health conditions [4 patients], and others explained that it would take too much time [2 patients]). Therefore, the final number of patients included in this study was 176 ( 82 women and 94 men), which is $83.41 \%$ of the total number of patients approached. Participants ranged in age from 45 to 82 years $(M=58.56$, $S D=8.25)$. Specific health and demographic characteristics of the patients are given in Table 1.

Among the patients with coronary artery disease were people with a stable form, scheduled for invasive diagnostics (coronary angiography). In the subgroup with heart failure, there were most frequently patients admitted urgently due to the exacerbation of chronic heart failure (exertional dyspnoea - NYHA III, dyspnoea at rest - NYHA IV). In the subgroup of patients with arrhythmias, there were also patients who were admitted to the hospital in the scheduled and urgent mode.

\section{MATERIALS AND PROCEDURE}

Patients who met the above inclusion/exclusion criteria were approached by research assistants in the inpatient clinic and outpatient centre in a cardiology unit in Opole (Poland). The patients received information about the study and a questionnaire together with a written informed consent document. The questionnaire had to be completed either in the cardiology unit (inpatients clinic patients) or at home (outpatient centre patients) and was collected at the visit. After the study, participants were debriefed and given the contact information of the researcher in case of any questions or concerns. The ethics committee of the University of Opole approved this study procedure.

Meaning in life. The Meaning in Life Questionnaire (MLQ; Steger, Frazier, Oishi, \& Kaler, 2006) was used to assess meaning in life. The questionnaire measures two dimensions of meaning in life: presence and search. The presence subscale measures the extent to which participants perceive their lives as meaningful, while the search subscale measures the extent to which respondents are actively seeking meaning or purpose in their lives. Each subscale consists of five items rated on a 7-point Likert scale, ranging from 1 (strongly disagree) to 7 (strongly agree). In the current study only the presence subscale was used, as its aim was to assess the level of meaning in life experienced at a given moment of time (e.g., "I understand my life's meaning" and "My life has no clear purpose"). Research supported the convergent and discriminant validity of the MLQ (Steger et al., 2006; Steger \& Kashdan, 2007). Internal consistency reliability for the current study was .85 for the presence subscale. Krok (2011) adapted the Polish version of the MLQ.

Self-efficacy. The General Self-Efficacy Scale (GSE) by Schwarzer and Jerusalem (1995) was used in this study. The scale measures the general sense of perceived self-efficacy that refers to global confidence in ones' coping ability across a wide range of demanding or novel situations (e.g. "I can always manage to solve difficult problems if I try hard enough", "If I am in trouble, I can usually think of a solution"). It comprises ten items to which responses range from 1 (strongly disagree) to 4 (strongly agree). Higher scores on the scale indicate more levels of perceived general self-efficacy.

Table 1

Health and demographic characteristics of patients

\begin{tabular}{lcc}
\hline Patients & $M$ & $S D$ \\
\hline Age & 58.56 & 8.25 \\
Body mass index & 27.01 & 0.51 \\
\hline & $N$ & $\%$ \\
\hline
\end{tabular}

Sex

Male 94

Female 82

Health characteristics

$\begin{array}{lll}\text { Coronary artery disease } & 55 & 31.25 \\ \text { Heart failure } & 38 & 21.59 \\ \text { Heart defects } & 41 & 23.30 \\ \text { Cardiac arrhythmia } & 42 & 23.86\end{array}$

Marital status

Married/cohabited

$144 \quad 81.82$

Single

$32 \quad 18.18$

Education

Elementary school education $\quad 21 \quad 11.93$

Basic vocational education $\quad 46 \quad 26.14$

High school education $\quad 74 \quad 42.05$

University education $\quad 35 \quad 19.88$ 
Table 2

Pearson $R$ correlations among meaning in life, self-efficacy, and subjective well-being

\begin{tabular}{|c|c|c|c|c|c|c|c|}
\hline & $M$ & $S D$ & 1 & 2 & 3 & 4 & 5 \\
\hline 1. Meaning in life & 4.59 & 0.86 & - & & & & \\
\hline 2. Self-efficacy & 2.26 & 0.41 & $.52^{* * *}$ & - & & & \\
\hline 3. Life satisfaction & 4.09 & 1.13 & $.51^{* * *}$ & $.59^{* * *}$ & - & & \\
\hline 4. Positive affect & 3.11 & 0.63 & $.52^{* * *}$ & $.54^{* * *}$ & $.57^{* * *}$ & - & \\
\hline 5. Negative affect & 2.30 & 0.66 & $-.31^{* * *}$ & $-.41^{* * *}$ & $-.44^{* * *}$ & $-.31^{* * *}$ & - \\
\hline
\end{tabular}

The high validity and reliability of the scale have been demonstrated in many studies across various research contexts and ethnically diverse populations (e.g., Luszczynska, Gutierrez-Dona, \& Schwarzer, 2005). Cronbach's $\alpha$ coefficient for the present study was .90 . Schwarzer, Jerusalem, and Juczyński (Juczyński, 2001) adapted the Polish version of the GSE.

Subjective well-being. Two scales measuring the cognitive and affective dimension of subjective wellbeing were used. The Satisfaction With Life Scale (SWLS; Diener, Emmons, Larsen, \& Griffin, 1985) is a widely used measure which assesses global cognitive judgments of subjective well-being. The SWLS assesses the respondents' satisfaction with life as a whole and does not tap related constructs such as positive affect or loneliness (e.g. "In most ways my life is close to my ideal", "The conditions of my life are excellent"). It consists of five items rated from 1 (absolutely untrue) to 7 (absolutely true). Higher scores indicate greater satisfaction with life. The alpha coefficient for the present study was .85. Juczyński (2001) adapted the Polish version of the SWLS.

The Positive and Negative Affect Schedule (PANASX; Watson \& Clark, 1994) evaluates the affective component of subjective well-being in two main domains, positive and negative affect, as well as in 11 more specific affects which are measured using a 5-point scale, ranging from 1 (very slightly or not at all) to 5 (extreme$l y)$. In the current study, we only used positive and negative affect subscales (ten items in each subscale, e.g. "cheerful", "happy", "sad", "upset"). The Cronbach $\alpha$ coefficients for the present study were .83 and .85 , respectively. The Polish version of the PANAS-X adapted by Krok (2009) was used in the current study.

\section{RESULTS}

\section{RELATIONSHIPS AMONG MEANING IN LIFE, SELF-EFFICACY, AND SUBJECTIVE WELL-BEING}

First, bivariate associations among meaning in life, self-efficacy, and cognitive and affective dimensions of subjective well-being were calculated, and are pre- sented in Table 2 . The statistical analyses revealed that meaning in life was positively related to self-efficacy, life satisfaction, and positive affect, but negatively related to negative affect. Self-efficacy positively correlated with life satisfaction and positive affect, but negatively correlated with negative affect. As regards the internal associations between cognitive and affective dimensions of well-being, life satisfaction was positively related to positive affect and negatively related to negative affect.

In order to compare the correlations between meaning in life, self-efficacy and the dimensions of subjective well-being, tests of the difference were conducted. There was a significant difference between the correlations of meaning in life with life satisfaction and meaning in life with negative affect $(p<.001)$, but not with positive affect $(p=.899)$. In addition, the correlation of self-efficacy with life satisfaction significantly differed from the correlation of self-efficacy with negative affect $(p<.001)$, but not with positive affect $(p=.494)$.

\section{SELF-EFFICACY AS A MEDIATOR OF THE RELATIONSHIP BETWEEN MEANING IN LIFE AND SUBJECTIVE WELL-BEING}

To examine the relationships between meaning in life and subjective well-being, and the possible mediational role of self-efficacy, path analysis was used to test the proposed model and study hypotheses. The analysis was performed for the cognitive and affective dimensions of subjective well-being, which enables us to compare their underlying different processes of human functioning, i.e. cognition and affect. The analysis was conducted to estimate the direct and indirect paths as depicted in Figure 1. All analyses were based on the covariance matrix and maximum likelihood estimation as implemented in AMOS 21 (Arbuckle, 2012).

The initial model, which consisted of five observed variables (meaning in life as an independent variable; life satisfaction, positive affect and negative affect as dependent variables; and self-efficacy as a media- 


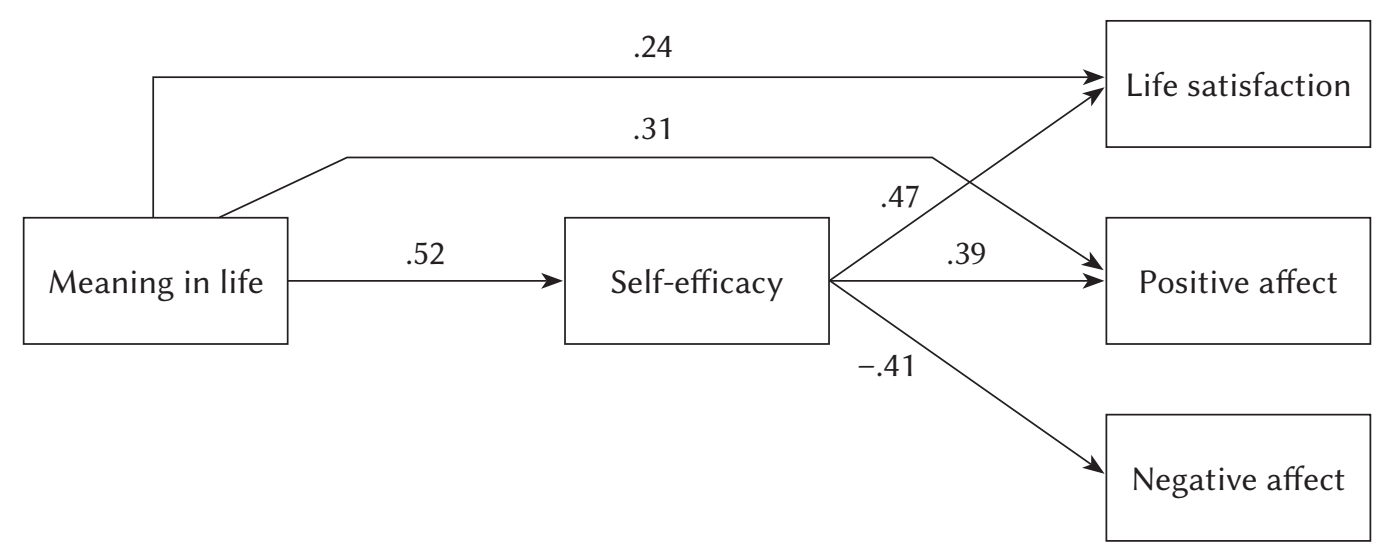

Figure 2. Mediation model of self-efficacy in the relation between meaning in life and the cognitive and affective dimensions of subjective well-being.

Table 3

Bootstrapping standardized direct and indirect effects and 95\% confidence intervals for the final mediational model

\begin{tabular}{|c|c|c|c|}
\hline \multirow[t]{2}{*}{ Model pathways } & \multirow{2}{*}{$\begin{array}{c}\text { Standardised } \\
\text { estimates }\end{array}$} & \multicolumn{2}{|c|}{$95 \%$ Confidence intervals } \\
\hline & & Lower & Upper \\
\hline Meaning in life $\rightarrow$ Life satisfaction & $.24^{\mathrm{a}}$ & .10 & .38 \\
\hline Meaning in life $\rightarrow$ Positive affect & $.31^{\mathrm{a}}$ & .16 & .46 \\
\hline Meaning in life $\rightarrow$ Self-efficacy $\rightarrow$ Life satisfaction & $.25^{\mathrm{a}}$ & .17 & .34 \\
\hline Meaning in life $\rightarrow$ Self-efficacy $\rightarrow$ Positive affect & $.20^{\mathrm{a}}$ & .12 & .30 \\
\hline Meaning in life $\rightarrow$ Self-efficacy $\rightarrow$ Negative affect & $-.22^{\mathrm{a}}$ & -.31 & -.13 \\
\hline
\end{tabular}

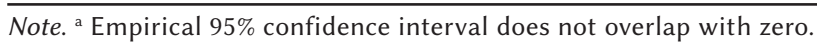

tor) and both direct and indirect paths among them did not obtain a satisfactory fit to the data: $\chi^{2}=7.32$, $p<.001$; GFI $=.95 ; \mathrm{NFI}=.67$; CFI $=.66$; $\mathrm{RMSEA}=.19$. The direct path from meaning in life to negative affect was statistically insignificant $(\beta=-.14, p=.084)$. According to the modification procedures, the initial model was re-tested; the path from meaning in life to negative affect was removed and covariance between life satisfaction, positive affect, and negative affect was added. After the modifications, the results showed a good fit to the data: $\chi^{2}=5.76, p<.001$; $\mathrm{GFI}=.99 ; \mathrm{NFI}=.94 ; \mathrm{CFI}=.97 ; \mathrm{RMSEA}=.07$ (Figure 2).

The path analysis results showed significant direct effects of meaning in life on life satisfaction $(\beta=.24$, $p=.002)$ and positive affect $(\beta=.31, p=.001)$. The effect of meaning in life on self-efficacy was significant $(\beta=.52, p<.001)$. The results also showed significant effects of self-efficacy on life satisfaction $(\beta=.47$, $p<.001)$, positive affect $(\beta=.39, p=.001)$ and negative affect $(\beta=-.41, p<.001)$. The regression coefficients of all paths were standardized.

The bootstrap estimation procedure (a bootstrap sample of 1000 was specified) was used to test the significance of the mediation effects of self-efficacy on the relationship between meaning in life and life satisfac- tion, positive affect, and negative affect. As suggested by MacKinnon, Lockwood, and Williams (2004), this method can generate the most accurate confidence intervals for indirect effects. Moreover, the significance of the total indirect effect in multiple mediator models is not a necessary precondition for significant specific indirect effects (Preacher \& Hayes, 2008). As displayed in Table 3, meaning in life had direct significant effects on life satisfaction and positive affect. In contrast, as the final mediational model revealed, there was no direct effect of meaning in life on negative affect. Selfefficacy was found to be a partial mediator of the relationship between meaning in life with life satisfaction and positive affect. As there was no direct path between meaning in life and negative affect, meaning in life was found to be a full mediator between these factors. Therefore, meaning in life exerted significant indirect effects on life satisfaction, positive affect, and negative affect through self-efficacy.

\section{DISCUSSION}

The purpose of the present study was to examine the role of self-efficacy in the relationship between 
meaning in life and subjective well-being. Our study demonstrated relationships among the above factors and revealed that self-efficacy is a significant mediator of the relationship between purpose-oriented personality trait and subjective well-being of cardiac patients.

Correlational analyses showed that meaning in life and self-efficacy were significantly related to each other and also to dimensions of subjective well-being. It is consistent with previous studies demonstrating that meaning in life and self-efficacy correlate with well-being and quality of life (Dezutter et al., 2015; Jafary et al., 2011). Meaning in life and self-efficacy were positively related to two dimensions of subjective well-being - life satisfaction and positive affect - but negatively related to negative affect. Our data support the results of other studies, which indicate that meaning in life and self-efficacy are significantly associated with cardiac patients' well-being (Joekes et al., 2007; Park et al., 2008). These findings confirm our first and second hypothesis, which assumed such relationships. They also extend previous results by showing that meaning in life and self-efficacy are related to both dimensions of cardiac patients' subjective well-being - its cognitive and affective spheres. It appears to be an interesting result as it reveals that motivationally oriented personality traits (i.e. meaning in life, self-efficacy) are associated with cognitive and affective processes responsible for achieving happiness and satisfaction among cardiac patients.

We hypothesized that the relationship between meaning in life and both cognitive and affective dimensions of subjective well-being would be mediated by self-efficacy (third and fourth hypothesis). Using path analysis we observed the direct effects of meaning in life on life satisfaction and positive affect and indirect effects of meaning in life on life satisfaction, positive affect, and negative affect. However, we did not observe a significant path between meaning in life and negative affect in our study, which suggests that the mediation pattern between meaning in life and positive affect is different from the pattern regarding meaning in life and negative affect. The model including negative affect is a case of indirect-only mediation (Zhao, Lynch Jr, \& Chen, 2010), in which the mediated effect exists (by an indirect path), but there is no significant direct effect. The current study thus contributes to the previous knowledge by pointing to the different types of relationships between meaning in life and affective factors.

This result can be justified by the fact that the predictors of positive affect and negative affect differ from each other. Zika and Chamberlain (1992) and Steger and colleagues (2006) stated that meaning in life is related to both kinds of affect. Those assumptions were not supported by more advanced analyses such as path analysis. Furthermore, Karademas (2007) believes that other personality traits, espe- cially neuroticism, are better predictors of negative affect. Further research should focus on finding better predictors of negative affect. Since lower levels of self-efficacy are related to the symptoms of anxiety or depression (Pajares, 1996; Schwarzer et al., 1997), it might be important to verify the predictive role of those two personality variables in the process of shaping cardiac patients' negative affect.

The results confirmed our third and fourth hypotheses, which had a strong theoretical and empirical background. They are consistent with the two theoretical models presented earlier: the cognitiveaffective processing system (Mischel \& Shoda, 1995) and the self-concordance model (Sheldon \& Copper, 2008). They also proved the significance of previous empirical results showing the mediational role of affective states (i.e. levels of optimism or self-efficacy) in the relationship between purpose-oriented personality traits (i.e. meaning in life or sense of coherence) and well-being (Ho et al., 2010; Karademas, 2006; Krok \& Telka, 2018). To our knowledge, this is the first study on cardiac patients to demonstrate the mediational role of self-efficacy in the relationship between meaning in life and subjective well-being's dimensions.

It is important to highlight the significant role of self-efficacy in shaping the subjective well-being of cardiac patients, since it has an important role in coping with stress (Schwarzer et al., 1997). Chronic illness, such as coronary heart disease, might increase the level of perceived distress and then negatively influence the well-being and quality of life of cardiac patients. Experiencing negative cognitive and affective reactions, cardiac patients tend to rely on their motivational resources, e.g. self-efficacy, in order to maintain a satisfactory level of meaning in life, which in turn imbues their life with a sense of purpose and significance, and strengthens coping abilities. This view is supported by research demonstrating that self-efficacy is a very important determinant of behavioural changes related to well-being in people suffering from serious illnesses (Bandura, 1993; RobinsonSmith et al., 2000). As Sullivan and colleagues (1998) showed, self-efficacy improvement also has a broader application in the functioning of cardiac patients as it helps to improve the physical and social functioning of coronary heart disease patients.

\section{LIMITATIONS}

Although our study produced important results, it is not free of limitations. First, our data were based on a nonrandomized sample. Second, although our mediation model is tested as causal, it does not allow us to establish cause and effect relationships, since our data are cross-sectional. It would require longitudinal studies to confirm whether the proposed direc- 
tion of the influence is correct. Third, we also measured only one dimension of well-being - its hedonic sphere. Further research should include other measures of well-being to more broadly verify the role of meaning in life and self-efficacy in cardiac patients' psychological functioning, as meaning in life and self-efficacy are also important predictors of psychological well-being in chronic patients (Dezutter et al., 2015; Joekes et al., 2007). Finally, despite taking into account the type of heart disease of the study participants, we did not take into account the duration of their disease. In the case of clinical samples such as cardiac patients, the duration of the disease should be taken into account, since it can significantly differentiate the results of the study participants.

\section{CONCLUSIONS}

To conclude, the present study shows the complexity of the relationship between purpose-oriented personality trait and chronic patients' well-being. To our knowledge, it is one of the first studies to point out the mediating role of self-efficacy in the relationship of meaning in life and subjective well-being in a group of cardiac patients. The results obtained in our study allow clinicians to better understand the functional mechanisms by which meaning in life is associated with the cognitive and affective dimensions of subjective well-being. This gives a solid foundation for further investigation of the influence of personality traits on psychosocial functioning of cardiac patients.

\section{REFERENCES}

Arbuckle, J. L. (2012). Users Guide. IBM ${ }^{\circledR}$ SPSS ${ }^{\circledR}$ Amos $^{\mathrm{TM}} 21$

Arvidsdotter, T., Marklund, B., Taft, C., \& Kylén, S. (2015). Quality of life, sense of coherence and experiences with three different treatments in patients with psychological distress in primary care: a mixed-methods study. BMC Complementary and Alternative Medicine, 15, 132-143. https://doi. org/10.1186/s12906-015-0654-z

Bandura, A. (1978). Self-efficacy: Toward a unifying theory of behavioral change. Advances in Behaviour Research and Therapy, 1, 139-161. https://doi. org/10.1016/0146-6402(78)90002-4

Bandura, A. (1982). Self-efficacy mechanism in human agency. American Psychologist, 37, 122-147. https://doi.org/10.1037/0003-066X.37.2.122

Bandura, A. (1993). Perceived self-efficacy in cognitive development and functioning. Educational Psychologist, 28, 117-148. https://doi.org/10.1207/ s15326985ep2802_3

Bandura, A. (1995). Self-efficacy in changing societies. Cambridge: Cambridge University Press.
Blackburn, L., \& Owens, G. P. (2015). The effect of self-efficacy and meaning in life on posttraumatic stress disorder and depression severity among veterans. Journal of Clinical Psychology, 71, 219228. https://doi.org/10.1002/jclp.22133

Błażek, M., Kaźmierczak, M., \& Besta, T. (2015). Sense of purpose in life and escape from self as the predictors of quality of life in clinical samples. Journal of Religion and Health, 54, 517-523. https://doi. org/10.1007/s10943-014-9833-3

Byun, M. K., Hyun, H. K., Park, S. J., \& Choi, E. Y. (2017). Efficacy of well-being program for meaning of life, self-efficacy, and successive aging in the elderly. Journal of the Korea Academia - Industrial Cooperation Society, 18, 413-422. https://doi. org/10.5762/KAIS.2017.18.10.413

Calandri, E., Graziano, F., Borghi, M., \& Bonino, S. (2018). Depression, positive and negative affect, optimism and health-related quality of life in recently diagnosed multiple sclerosis patients: the role of identity, sense of coherence, and self-efficacy. Journal of Happiness Studies, 19, 277-295. https://doi.org/10.1007/s10902-016-9818-x

Chamberlain, K., \& Zika, S. (1988). Religiosity, life meaning and wellbeing: Some relationships in a sample of women. Journal for the Scientific Study of Religion, 27, 411-420. https://doi.org/10.2307/1387379

Craner, J., Douglas, K. V., Dierkhising, R., Hathaway, J., Goel, K., \& Thomas, R. J. (2017). Associations of baseline depressed mood and happiness with subsequent well-being in cardiac patients. Social Science and Medicine, 174, 209-212. https:// doi.org/10.1016/j.socscimed.2016.12.013

DeWitz, S. J., Woolsey, M. L., \& Walsh, W. B. (2009). College student retention: An exploration of the relationship between self-efficacy beliefs and purpose in life among college students. Journal of College Student Development, 50, 19-34. https:// doi.org/10.1353/csd.0.0049

Dezutter, J., Luyckx, K., \& Wachholtz, A. (2015). Meaning in life in chronic pain patients over time: associations with pain experience and psychological well-being. Journal of Behavioral Medicine, 38, 384-396. https://doi.org/10.1007/s10865-014-9614-1

Diener, E. (2009). The science of well-being. Social Indicators Research Series, 37, 11-58. https://doi. org/10.1007/978-90-481-2350-6_2

Diener, E. D., Emmons, R. A., Larsen, R. J., \& Griffin, S. (1985). The satisfaction with life scale. Journal of Personality Assessment, 49, 71-75. https://doi. org/10.1207/s15327752jpa4901_13

Frankl, V. E. (1963). Man's search for meaning: An introduction to logotherapy. New York: Washington Square Press.

Guerrero-Torrelles, M., Monforte-Royo, C., RodríguezPrat, A., Porta-Sales, J., \& Balaguer, A. (2017). Understanding meaning in life interventions in patients with advanced disease: A systematic review 
and realist synthesis. Palliative Medicine, 31, 798813. https://doi.org/10.1177/0269216316685235

Ho, K. K., Pinsky, J. L., Kannel, W. B., \& Levy, D. (1993). The epidemiology of heart failure: The Framingham Study. Journal of the American College of Cardiology, 22, 6-13. https://doi.org/10.1016/07351097(93)90455-A

Ho, M. Y., Cheung, F. M., \& Cheung, S. F. (2010). The role of meaning in life and optimism in promoting well-being. Personality and Individual Differences, 48, 658-663. https://doi.org/10.1016/j.paid.2010.01.008

Jafary, F., Farahbakhsh, K., Shafiabadi, A., \& Delavar, A. (2011). Quality of life and menopause: Developing a theoretical model based on meaning in life, self-efficacy beliefs, and body image. Aging and Mental Health, 15, 630-637. https://doi.org/10. 1080/13607863.2010.548056

Joekes, K., Van Elderen, T., \& Schreurs, K. (2007). Selfefficacy and overprotection are related to quality of life, psychological well-being and self-management in cardiac patients. Journal of Health Psychology, 12, 4-16. https://doi.org/10.1177/1359105306069096

Juczyński, Z. (2001). Narzędzia pomiaru w promocji i psychologii zdrowia [Tools of measurement in the promotion and psychology of health]. Warszawa: Pracownia Testów Psychologicznych PTP.

Karademas, E. C. (2006). Self-efficacy, social support and well-being: The mediating role of optimism. Personality and Individual Differences, 40, 12811290. https://doi.org/10.1016/j.paid.2005.10.019

Karademas, E. C. (2007). Positive and negative aspects of well-being: Common and specific predictors. Personality and Individual Differences, 43, 277-287. https://doi.org/10.1016/j.paid.2006.11.031

Krok, D. (2009). Religijność a jakość życia w perspektywie mediatorów psychospołecznych [Religiousness and quality of life in the perspective of psychosocial mediators]. Opole: Redakcja Wydawnictw WTUO.

Krok, D. (2011). Poczucie sensu życia a dobrostan psychiczny [Meaning in life and well-being]. Psychologia Jakości Życia, 10, 95-115.

Krok, D. (2015a). The role of meaning in life within the relations of religious coping and psychological well-being. Journal of Religion and Health, 54, 22922308. https://doi.org/10.1007/s10943-014-9983-3

Krok, D. (2015b). The mediating role of optimism in the relations between sense of coherence, subjective and psychological well-being among late adolescents. Personality and Individual Differences, 85, 134-139. https://doi.org/10.1016/j.paid.2015.05.006

Krok, D., \& Telka, E. (2018). Optimism mediates the relationships between meaning in life and subjective and psychological well-being among late adolescents. Current Issues in Personality Psychology, 7, 32-42. https://doi.org/10.5114/cipp.2018.79960

Liu, C., Cheng, Y., Hsu, A. S., Chen, C., Liu, J., \& Yu, G. (2018). Optimism and self-efficacy mediate the association between shyness and subjective well- being among Chinese working adults. PloS One, 13, e0194559. https://doi.org/10.1371/journal.pone. 0194559

Luszczynska, A., Gutierrez-Dona, B., \& Schwarzer, R. (2005). General self-efficacy in various domains of human functioning: Evidence from five countries. International Journal of Psychology, 40, 80-89. https://doi.org/10.1080/00207590444000041

Magaletta, P. R., \& Oliver, J. M. (1999). The hope construct, will, and ways: Their relations with self-efficacy, optimism, and general well-being. Journal of Clinical Psychology, 55, 539-551. https://doi.org/ 10.1002/(SICI)1097-4679(199905)55:5<539::AIDJCLP2>3.0.CO;2-G

Machell, K. A., Kashdan, T. B., Short, J. L., \& Nezlek, J. B. (2015). Relationships between meaning in life, social and achievement events, and positive and negative affect in daily life. Journal of Personality, 83, 287-298. https://doi.org/10.1111/jopy. 12103

MacKinnon, D. P., Lockwood, C. M., \& Williams, J. (2004). Confidence limits for the indirect effect: Distribution of the product and resampling methods. Multivariate Behavioral Research, 39, 99-128. https://doi.org/10.1207/s15327906mbr3901_4

McGee, H. (2007). Health-related quality of life in cardiac patients. In J. Perk, P. Mathes, H. Gohlke, C. Monpère, I. Hellemans, H. McGee, P. Sellier, \& H. Saner (Eds.), Cardiovascular prevention and rehabilitation (pp. 256-268). London: Springer.

Mischel, W., \& Shoda, Y. (1995). A cognitive-affective system theory of personality: Reconceptualizing situations, dispositions, dynamics, and invariance in personality structure. Psychological Review, 102, 246-268. https://doi.org/10.1037/0033-295X.102.2.246 Pajares, F. (1996). Self-efficacy beliefs in academic settings. Review of Educational Research, 66, 543578. https://doi.org/10.3102/00346543066004543

Park, C. L., Malone, M. R., Suresh, D. P., Bliss, D., \& Rosen, R. I. (2008). Coping, meaning in life, and quality of life in congestive heart failure patients. Quality of Life Research, 17, 21-26. https://doi. org/10.1007/s11136-007-9279-0

Preacher, K. J., \& Hayes, A. F. (2008). Asymptotic and resampling strategies for assessing and comparing indirect effects in multiple mediator models. Behavior Research Methods, 40, 879-891. https:// doi.org/10.3758/BRM.40.3.879

Robinson-Smith, G., Johnston, M. V., \& Allen, J. (2000). Self-care self-efficacy, quality of life, and depression after stroke. Archives of Physical Medicine and Rehabilitation, 81, 460-464. https://doi. org/10.1053/mr.2000.3863

Roger, V. L., Go, A. S., Lloyd-Jones, D. M., Adams, R. J., Berry, J. D., Brown, T. M., ... \& Wylie-Rosett, J. (2011). Heart disease and stroke statistics - 2011 update: a report from the American Heart Association. Circulation, 123, e18-e209. https://doi. org/10.1161/CIR.0b013e3182009701 
Ryff, C. D. (1989). Happiness is everything, or is it? Explorations on the meaning of psychological wellbeing. Journal of Personality and Social Psychology, 57, 1069-1081. https://doi.org/10.1037/00223514.57.6.1069

Schulenberg, S. E., Smith, C. V., Drescher, C. F., \& Buchanan, E. M. (2016). Assessment of meaning in adolescents receiving clinical services in Mississippi following the Deepwater Horizon oil spill: An application of the Purpose in Life Test - Short Form (PIL-SF). Journal of Clinical Psychology, 72, 1279-1286. https://doi.org/10.1002/jclp.22240

Schwarzer, R., Bäßler, J., Kwiatek, P., Schröder, K., \& Zhang, J. X. (1997). The assessment of optimistic self-beliefs: comparison of the German, Spanish, and Chinese versions of the general self-efficacy scale. Applied Psychology, 46, 69-88. https:// doi.org/10.1111/j.1464-0597.1997.tb01096.x

Schwarzer, R., \& Jerusalem, M. (1995). Generalised Self-Efficacy Scale. In J. Weinman, S. Wright, \& M. Johnston (Eds.), Measures in health psychology: A user's portfolio. Causal and control beliefs (pp. 35-37). Windsor, UK: Nfer-Nelson.

Sheldon, K. M., \& Cooper, M. L. (2008). Goal striving within agentic and communal roles: Separate but functionally similar pathways to enhanced wellbeing. Journal of Personality, 76, 415-448. https:// doi.org/10.1111/j.1467-6494.2008.00491.x

Steger, M. F. (2012). Making meaning in life. Psychological Inquiry, 23, 381-385. https://doi.org/10.108 0/1047840X.2012.720832

Steger, M. F., Frazier, P., Oishi, S., \& Kaler, M. (2006). The meaning in life questionnaire: assessing the presence of and search for meaning in life. Journal of Counseling Psychology, 53, 80-93. https://doi. org/10.1037/0022-0167.53.1.80

Steger, M. F., \& Kashdan, T. B. (2007). Stability and specificity of meaning in life and life satisfaction over one year. Journal of Happiness Studies, 8, 161-179. https://doi.org/10.1007/s10902-006-9011-8

Steger, M. F., Kashdan, T. B., Sullivan, B. A., \& Lorentz, D. (2008). Understanding the search for meaning in life: Personality, cognitive style, and the dynamic between seeking and experiencing meaning. Journal of Personality, 76, 199-228. https://doi.org/10.1111/j.1467-6494.2007.00484.x

Strobel, M., Tumasjan, A., \& Spörrle, M. (2011). Be yourself, believe in yourself, and be happy: Self-efficacy as a mediator between personality factors and subjective well-being. Scandinavian Journal of Psychology, 52, 43-48. https://doi.org/10.1111/ j.1467-9450.2010.00826.x

Sullivan, M. D., Lacroix, A. Z., Russo, J., \& Katon, W. J. (1998). Self-efficacy and self-reported functional status in coronary heart disease: a six-month prospective study. Psychosomatic Medicine, 60, 473478. https://doi.org/10.1097/00006842-19980700000014
Watson, D., \& Clark, L. A. (1999). The PANAS-X: Manual for the positive and negative affect scheduleexpanded form. lowa: The University of Iowa.

Wong, P. T. (1998). Implicit theories of meaningful life and the development of the personal meaning profile. Mahwah, NJ: Lawrence Erlbaum Associates Publishers.

Wong, P. T. (2012). Toward a dual-systems model of what makes life worth living. In P.T. Wong (Ed.), The human quest for meaning (pp. 49-68). London, New York: Routledge.

Yoon, J. S. (2002). Teacher characteristics as predictors of teacher-student relationships: Stress, negative affect, and self-efficacy. Social Behavior and Personality: An International Journal, 30, 485-493. https://doi.org/10.2224/sbp.2002.30.5.485

Zhao, X., Lynch Jr, J. G., \& Chen, Q. (2010). Reconsidering Baron and Kenny: Myths and truths about mediation analysis. Journal of Consumer Research, 37, 197-206. https://doi.org/10.1086/651257

Zika, S., \& Chamberlain, K. (1992). On the relation between meaning in life and psychological wellbeing. British Journal of Psychology, 83, 133-145. https://doi.org/10.1111/j.2044-8295.1992.tb02429.x 